\title{
Antes de la ciudad agonal: Vía chilena, socialismo y vida citadina en el Santiago de Allende ${ }^{1}$
}

\section{Before the Agonal City: The Chilean Road to Socialism and Urban Culture in the Santiago de Allende}

\author{
Gonzalo Cáceres ${ }^{2}$ \\ Pontificia Universidad Católica de Chile (Chile)
}

Recibido: 29-05-15

Aprobado: 29-06-15

\section{Resumen}

El artículo analiza algunos de los procesos urbanos que preceden y suceden la instalación del gobierno de Allende, bajo la consigna respecto a que no existen ideas políticas sin espacio al cual sean referibles, ni espacios o principios espaciales a los que no correspondan ideas políticas. Con arreglo a algunos episodios verificados en 1970, se analizan diversas tensiones que tienen a la ciudad como escenario y que refieren a procesos de suburbanización residencial, pero también

\footnotetext{
${ }^{1}$ El presente artículo se beneficia de las discusiones y hallazgos producidos por el proyecto Fondecyt \#11304888 “Gentrificación de barrios populares: amenaza dedesplazamiento, potencial de integración e implicancias de política urbana en Santiagode Chile y Ciudad de México”.

${ }^{2}$ (gonzalo.caceres.quiero@gmail.com). Profesor Asociado, Instituto de Estudios Urbanos y Territoriales, Facultad de Arquitectura, Diseño y Estudios Urbanos, Pontificia Universidad Católica de Chile y del Centro de Desarrollo Urbano Sustentable (CEDEUS). Historiador y planificador urbano. Doctor (c) en Ciencias Sociales por la Universidad Nacional de Quilmes, Argentina. Publicaciones: Cáceres, G., Sabatini, F. Espacio público en el Santiago del bicentenario. In: Patricia Ramírez, editora. Las disputas por la ciudad. México: Miguel Angel Porrúa; 2014. p. 271-285; Cáceres, G., Salcedo, R., Campos, D.. Mall. In: Topalov, Ch.,editores. A aventura das palavras da cidade. Sao Paulo: Romano; 2014. p. 391-395; Cáceres, G., Voces encomiásticas sobre la ciudad. In: María de los Angeles Cornejos, editora. Archivo. Diálogos iniciales. Santiago de Chile: Ediciones Departamento de Artes Visuales de la Facultad de Artes Universidad de Chile; 2014. p. 109-111; Cáceres, G., Millán, R. El Santiago de Pinochet: represión, autoritarismo e institucionalización (1973-1981). Registros-Revista de Investigación Histórica. 2014; 10 (11):150-165; Cáceres, G. La construcción del memorial en la ciudad: inscripciones sobre los derechos humanos en el Santiago (pos) dictatorial. Revista Persona y Sociedad, 2012; XXVI (3): 53-66.
} 
de urbanización popular. Con arreglo a lugares, sitios y hasta calles, se propone una reflexión sobre las relaciones entre la política chilena y un Santiago cada vez más contencioso.

Palabras-clave: Vía chilena al Socialismo, Santiago, Salvador Allende, Unidad Popular.

\begin{abstract}
The article analyzes some of the urban processes that precede and succeed the installation of the Allende government, under the premise concerning that there are no politics without space to which they are referable, space or spaces or principles that do not correspond politics. Under some episodes verified in 1970, various tensions that have the city as stage and refer to processes of residential suburbanization, but also popular urban development are analyzed. Under places, sites and even streets, a reflection on the relations between Chilean politics and an increasingly contentious Santiago is proposed.
\end{abstract}

Key-words: The Chilean Road to Socialism, Santiago, Salvador Allende, Popular Unity.

\title{
Introducción
}

Varios serían los factores que elevan el atractivo de un país con independencia de su mayor o menor desarrollo relativo. La presencia, aislada o combinada, de recursos paisajísticos, dinamismo económico, patrimonio natural y estabilidad política, suelen ser destacados por el marketing de localidades (Kotler et. al. 2007). Pero no todas son amenidades y atributos predecibles. En ciertas coyunturas, las mudanzas sociales, culturales o ideológicas, pueden despertar interés por acotado que pareciera ser su "público objetivo". Es lo que pareciera suscitar en algunos públicos el "giro a la izquierda" que se estaría registrando en diferentes naciones latinoamericanas (Levitsky 2011). Más allá de la polémica interpretativa que disparan dichas experiencias, la región presenciaría hoy, como también ocurrió ayer, un ciclo de transformaciones cautivantes y políticamente sobredeterminadas.

Vistas longitudinalmente, hay biografías nacionales que admitirían la etiqueta de país-laboratorio. Chile, antes, durante y después de los largos sesentas, reuniría requisitos para ser calificada así (Magasich 1998; Klein 2010). Confirmarían su radical singularidad el carácter refundacional que exhibió revolución en libertad, la vía chilena al socialismo y, rota la tradición republicana, la conjunción de militarismo con liberalismo ortodoxo (Vera 1977; Valdés 1989). 
La vía chilena al socialismo capturó una atención mundial, que a más de 40 años de su dramático desenlace, no ha remitido del todo. Ni las conflagraciones decimonónicas, ni los movimientos telúricos, ni la misma dictadura de Pinochet y su prolongada sobrevida, suscitaron una atracción tan amplia y sostenida. Después de Argelia, Cuba, Santo Domingo, Indonesia y en paralelo al Vietnam bélico, el experimento chileno (Labrousse 1973), sedujo, pero por razones completamente a distintas a las relacionadas con luchas independentistas o regresiones autoritarias. Aunque no se suele reconocer, la naturaleza institucional, electoral y pacífica de la vía chilena amplificó la nómina de observadores y simpatizantes. Republicanos y hasta liberales moderados se sintieron atraídos por una experiencia que se reconocía marxista sin ambages.

Pocos podrían discutir que el triunfo electoral de la UP (Unidad Popular) fue uno de los momentos estelares para la izquierda occidental. Pero a diferencia de casi todas las naciones de Europa del Este que habían sido damnificadas por una guerra y eran parte de la hegemonía soviética, el gobierno de Allende no provenía de una contienda bélica ni era un satélite moscovita. Anti-imperialista, el así llamado proyecto socialista buscó revolucionar desde el Estado una economía subdesarrollada por dependiente. Elevado a la condición de punto de llegada, el socialismo jugaba un papel substitutivo frente a una democracia supuestamente esclerotizada.

Lejos de cualquier unidad, la izquierda criolla incluía una verdadera constelación de sensibilidades políticas y declinaciones ideológicas. La mera trayectoria del partido donde militaba Salvador Allende aseguraba una peculiar combinación de populismo y socialismo (Drake 1992). El influjo del pensamiento desarrollista, presente en muchos de los principales tomadores de decisiones, incluyó a técnicos con experiencia profesional en Cuba y que, en algunos casos, habían trabajado para la Comisión Económica para América Latina (CEPAL). La pluralidad de fuerzas que confluyeron en la UP, registró la presencia de socialdemócratas de comportamiento institucionalista -un segmento de los cuales se marcharía a la oposición a medio gobierno-, pero también de socialcristianos de sensibilidad comunitarista-que se mantendrían en el partido federado de la UP-. Por fuera de la coalición y de la política parlamentaria, figuraba el Movimiento de Izquierda Revolucionaria (MIR). Pese a su autonomía respecto de la izquierda tradicional, el MIR tuvo presencia en algunas reparticiones específicas, muy especialmente en un departamento del Ministerio de Vivienda y Urbanismo (MINVU).

Pese a su heterogeneidad, la izquierda chilena terminó encorsetada en la dicotomía reforma-revolución. Más allá del dualismo, la tensión entre reformistas y revolucionarios adoptó un carácter aplicado cuando el debate sobre la finiquitación del Estado liberal cobró centralidad en el propio gobierno (Garcés 1974). Dicho debate se inició incluso antes que el gobierno comenzara 
su gestión y durante los 1043 días que se extendió la administración anidó más de un incordio.

Las discrepancias respecto a la transición al socialismo desde un régimen liberal tuvieron un cariz teórico, pero también metodológico. Para los militantes comunistas y social-demócratas, etiquetados frecuentemente como conservadores, la prioridad del gobierno popular era consolidar las conquistas sociales sin exponer a zozobras los avances conseguidos. Como contrapartida, para una fracción de la militancia socialista, pero también social-cristiana, era imperativo incentivar las movilizaciones populares sin gradualismos.

Ya como gobierno, la administración allendista debió enfrentar la hipermovilización que, en su largo ejercicio como oposición había patrocinado en la fábrica, en el campo, pero también en la calle. Pero, ¿qué hacer con la protesta popular ahora que eran gobierno? Y más en específico, ¿qué comportamiento adoptar frente a las tomas de tierras cuando actos puntuales de desposesión eran parte del repertorio habitual de comunistas y socialistas? El dilema, similar al que viviría el Frente Amplio en Montevideo hacia 1990 (Alvarez 2012), tuvo múltiples modulaciones. Por una parte, la izquierda gobernante, rechazó una reforma urbana que incluyera la estatización de la tierra y su posterior redistribución. Allende desestimó cualquier enajenación masiva de tierra urbana del mismo modo como rechazó emplear las expropiaciones como un instrumento de desposesión. Por otra parte, su administración declinó revivir la política de desalojos fuertemente instrumentada durante los primero años de la administración de Eduardo Frei (1964-1970). Más permisivo que represivo, Allende, lo mismo que los profesionales convocados a su gobierno, concibieron un ambicioso programa de intervenciones en vivienda apropiada y equipamiento comunitario que incluía, además, desde el congelamiento de los alquileres hasta el desarrollo de remodelaciones sin provocar el desarraigo de los ocupantes originales. Las intervenciones urbanas del gobierno de Allende se concentraron en Santiago. ¿Cómo entender tan fuerte prioridad? 
Imagen 1. Evolución espacial de Santiago de Chile 1940-1970

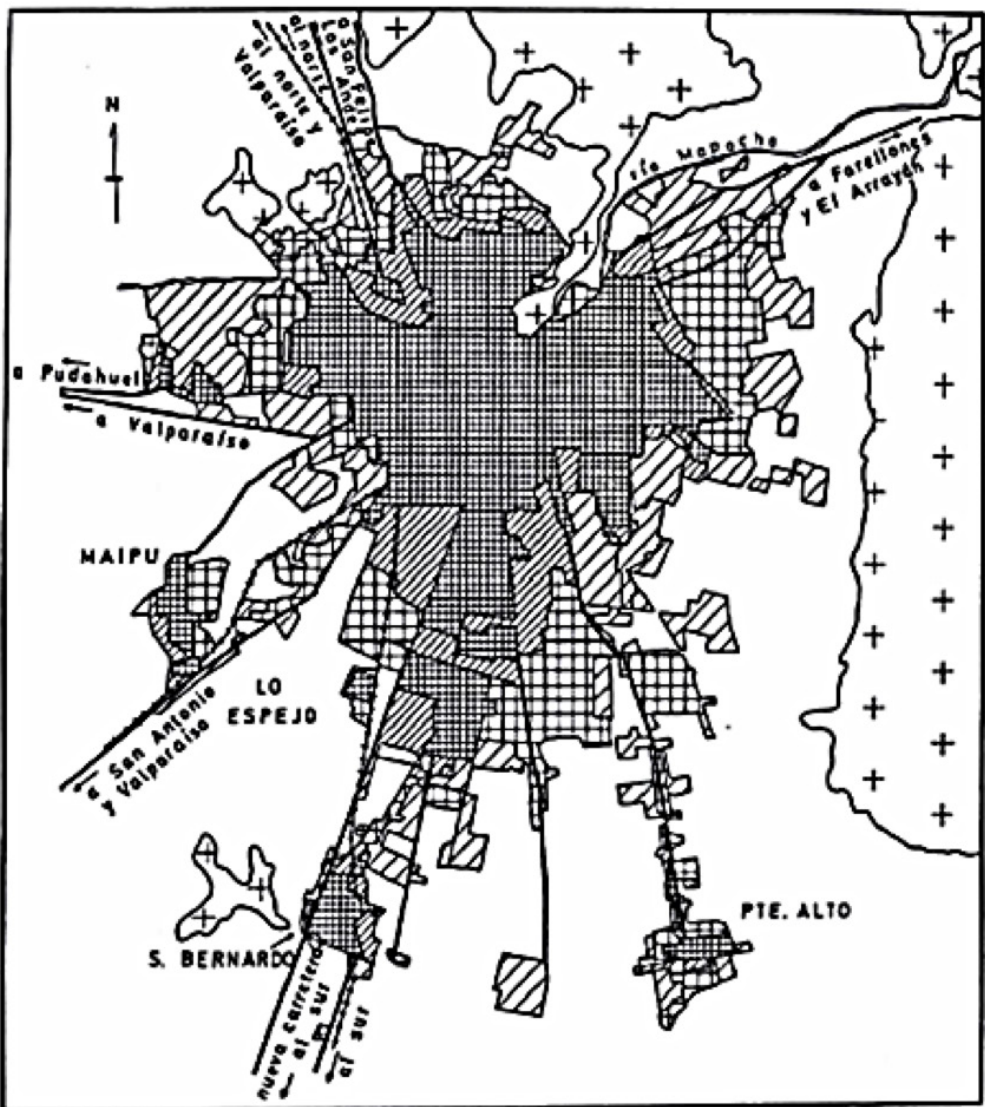

\begin{tabular}{|c|c|}
\hline \multicolumn{2}{|c|}{$\begin{array}{c}\text { SUPERFICIE } \\
\text { URAANA }\end{array}$} \\
\hline & 1960 \\
\hline & 1952 \\
\hline 开 & 1960 \\
\hline 772 & 1970 \\
\hline & CERROS \\
\hline
\end{tabular}
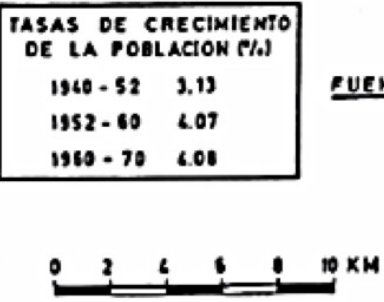

EUENTES:

LIGIA MERRERA J DIFERENTES MAPAS DE SANTIAGO.

MAPA BASE:

MAPA SANTIIOOO I: 100000 InSTITUTO GEOGRAFICO militaR

Pese a que Allende declaró un vínculo emocional con Valparaíso y jamás fue parlamentario representando a alguna circunscripción metropolitana, Santiago siempre fue una preocupación especial en su trabajo político. Varias son las razones que explican su atención, pero hay una particularmente 
importante: Santiago era la plaza electoral más grande del país, pero a Allende le tomó mucha dedicación despertar simpatías en el electorado de la ciudad. El diagnóstico, refrendado en cada una de las cuatro elecciones en las que compitió, se lo confidenció el propio candidato al periodista e historiador argentino Adolfo Gilly en el marco de los comicios de 1964. Sin llegar a ser anti-izquierdista, los votantes santiaguinos solía preferir presidenciables menos rupturistas. Aunque la indisposición ciudadana hacia posiciones tenidas por radicalizadas fue cediendo, sobrevivió entre los electores una fuerte valoración respecto del estatus de los postulantes. Por ejemplo, ser propietario de una vivienda en alguna de las comunas del barrio alto de la ciudad, fue un símbolo de éxito, pero también de prestigio. Allende, titular de una casa en la acomodada y homogénea comuna de Providencia, satisfacía, en parte, dicha preconcepción.

Pero, ¿qué importancia política podría tener vivir en uno u otro sector de una ciudad? Uno de los supuestos del artículo, es que el domicilio, la geografía socio-espacial, pero también la producción de símbolos sobre barrios y distritos, es relevante para el análisis político, pero también para el socio-cultural. Fiel a dicho predicamento, el artículo reflexiona sobre las intrincadas relaciones entre representaciones políticas, vida citadina y dinámica contenciosa. De una manera permanentemente situada, el argumento busca desplegar un análisis para el que no "(...) existen ideas políticas sin espacio al cual sean referibles, ni espacios o principios espaciales a los que no correspondan ideas políticas" (Cavalletti 2010: 7).

\section{Santiago capital}

Para la fracción mayoritaria de los inmigrantes que se trasladaron a Santiago, desplazarse a la capital incluía la posibilidad de empleo, educación y salud pública de más calidad que la que conocían en sus provincias. La ciudad, para un segmento de los extranjeros, despertaba, eso sí, sensaciones encontradas. En algunos casos, la magnificencia de las cordilleras que contornean la ciudad funcional, parecía exacerbar la decepción que provocaba recorrerla. Fue lo que le ocurrió a Juan José Sebreli (1968), ensayista y viajero impenitente. Para él, la materialidad construida que buena parte de la ciudad exhibía, le recordaba el Buenos Aires de fines del siglo XIX. En su aguda visión, fracciones completas de Santiago asomaban congeladas en una etapa hundida en el precapitalismo.

La explicación de tamaña frustración era mixta y podía ser atribuida a la ausencia relativa de edificios, a la presencia de un pericentro desangelado, pero también a la proliferación de barriadas. En cualquier caso, el Santiago que se disolvía en el campo, con sus vías muertas y terrenos baldíos, contrastaba con la atención que reclamaba una porción de la misma ciudad: el barrio alto. 
Cuidada vegetación, anchas veredas, calzadas pavimentadas e infraestructura actualizada entretejían un área suburbana que, salvo excepciones, exhibía baja o bajísima densidad. En ninguna parte como en esa se concentraban tantos chalets y mansiones, ni tampoco tantos automóviles ni colegios particulares.

Más allá de las representaciones, el barrio alto domiciliaba zonas de heterogeneidad social y funcional. Algo similar ocurría en el centro, aunque la diferencia principal radicaba en la combinación de verticalización, antigüedad, densidad y contigüidad. En no más de 100 manzanas, se alojaban las principales instalaciones del Estado, la Iglesia Católica, las principales empresas y comercios como consta en la canónica Guía de Santiago elaborada por Carlos Ossandón (1962) y en varias fotografías aéreas.

\section{Imagen 2. Santiago centro, 1964}

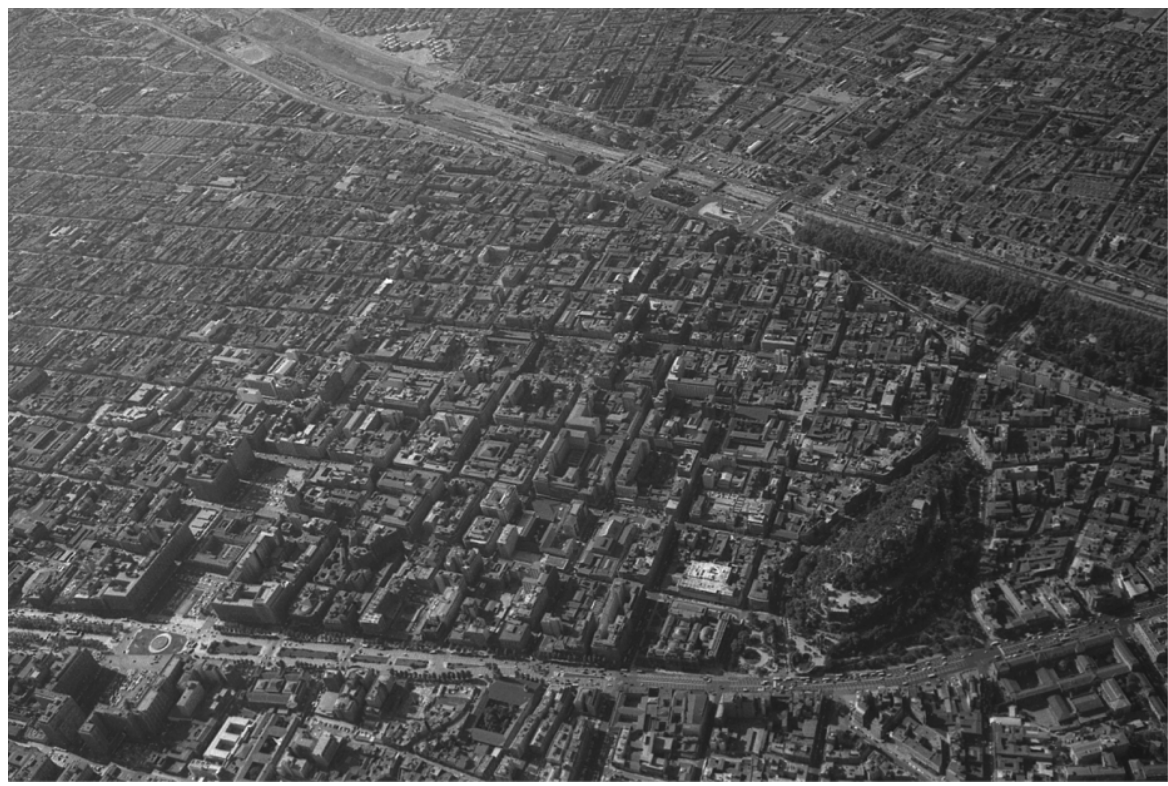

Fuente: http://www.archivovisual.cl/category/periodo/1951-2000

Incluso si contabilizamos la edificación pareada que exhibía una altura superior a los cuatro pisos, la nómina de calles-corredor provistas de alguna imponencia para el peatón, era exigua. Se podría argumentar que nuestro inventario busca excluir las galerías y pasajes que perforaban algunas de las manzanas y que le conferían a ciertos sectores del centro una mundanidad que en este rubro carecían Montevideo o Valparaíso. Es un elemento que matiza el juicio general, pero que no modifica la sobriedad del área central de 
Santiago, flagrante si la comparamos con el micro-centro de Buenos Aires con anterioridad a la definitiva peatonalización de calle Florida -1971 circa-.

En el centro también vivían suficientes arrendatarios y propietarios como para confirmar que se trataba de una zona mixta, la única en la ciudad que reunía servicios, educación, comercios y viviendas, muchas de ellas departamentos. Las industrias, al menos la mayoría de las pequeñas y muchas de las medianas, sobrevivían en el mismo perímetro u operaban en la franja pericéntrica.

Entre sus "vacíos", el centro de la ciudad contaba con algunos parques, plazas y plazoletas que alojaban o contorneaban los principales recintos fiscales. Si los entendemos como hitos, la nómina incluye dos parques. Uno longitudinal y ribereño (Forestal) y otro vertical (cerro Santa Lucía). Ambos, pero de diferentes maneras, señalizaron, durante buena parte del siglo XX, los límites del centro por el Norte y el Este. Hacia el Sur, la Alameda de las Delicias, que a la altura de La Moneda se extendía al modo de una avenida-parque en dirección hacia el camino nuevo que conectaba con la portuaria Valparaíso.

En torno al centro se contabilizan la mayoría de las avenidas existentes. Cuando Santiago fue sede del Mundial de Fútbol de 1962, su número no excedía la decena para toda la ciudad por mucho que hubiera varias vías que adoptaran dicha denominación. Ninguna, salvo La Alameda y una porción de Camps de Sports, podían ser asimiladas a un boulevard en cualquiera de los sentidos que conocemos del término.

La Alameda, una suerte de avenida-parque que atraviesa el centro de la ciudad, había labrado su importancia gracias a ciclos de intervención pública y privada. Su transformación en la principal arena pública de la ciudad comenzó a ocurrir sin que concluyera del todo la substitución de las mansiones neoclásicas que a fines del siglo XIX ya la contorneaban por ambos frentes.

Fiel a su jerarquía, parte importante de las más conocidas edificaciones republicanas se levantaron en sus costados hasta conformar un corredor provisto de una cierta unidad gracias al efecto de continuidad que generan las construcciones pareadas. Vista peatonalmente, la Alameda podemos caracterizarla como una franja mixta, residencial y también comercial, pero que reunía buena parte de la oferta cultural de carácter público que disponía la ciudad desde 1925 en adelante. 


\section{Imagen 3. La Alameda de Este a Oeste, 1964}

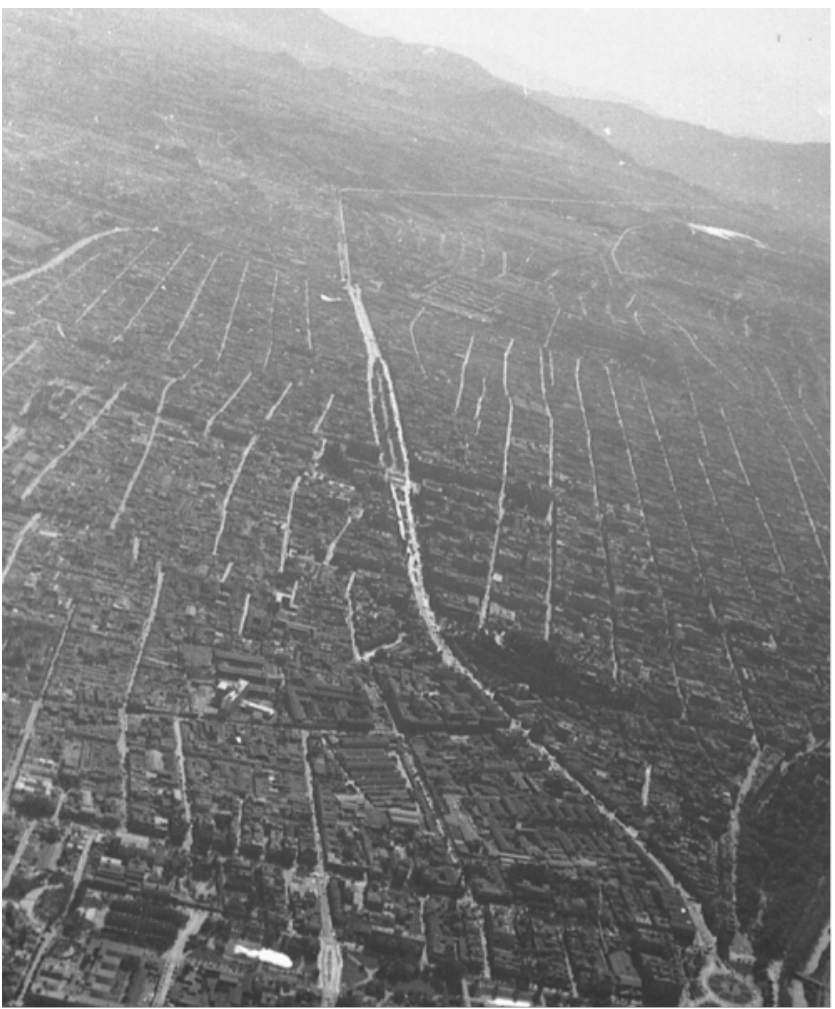

Fuente: http://www.archivovisual.cl/category/periodo/1951-2000

Que Allende haya evocado la Alameda en varias alocuciones confirma su simbolismo, pero también su funcionalidad. Para Allende, la Alameda reunía las amenidades que solo los lugares significativos pueden acrisolar y no lo era solo por sus dimensiones, por su conglomeración lineal de monumentos o por su promenade capaz de alojar puestos navideños.

Con frente a la Alameda transcurrió parte importante de su vida política universitaria en tanto que adherente del movimiento Avance. La lista de situaciones, episodios y acontecimientos que forjaron su identidad política, lo hermana con varias generaciones de socialistas, comunistas, masones, socialcristianos e independientes de izquierda, formados en la Universidad de Chile y cuya sede principal continúa enfrentando a la misma arteria.

Aunque se podrían mencionar muchos episodios que tuvieron lugar en La Alameda -desfiles, motines y hasta intentos de Golpe de Estado-, es 
importante recordar el interés que Allende le concedió a una exposición de talante vanguardista dedicada a la habitación higiénica (1939). La muestra, instalada con frente al aristocrático Club de La Unión, provocó cierto escándalo al exhibir fotografías de gran tamaño donde detallaba el cotidiano popular en ranchos y sitios tugurizados.

Como era presumible esperar, algunas concentraciones asociadas a sus consecutivas postulaciones presidenciales tuvieron dicho espacio como epicentro. En diferentes oportunidades, Allende se dirigió a sus simpatizantes reunidos en lo que todavía se entiende como la vía de mayor jerarquía de la ciudad. Misma situación aconteció cuando se festejó su triunfo presidencial. Después de tres intentos, Allende disfrutó la victoria que aunque estrecha, lo colocaba en posición de convertirse en mandatario. Corría septiembre de 1970 y la Alameda, que originalmente fuera denominada Campo de la Libertad Civil, fue el ámbito donde transcurrió una improvisada celebración. En simultáneo, carros blindados, en una cantidad que nunca se ha podido establecer con precisión, se desplegaron en otros puntos del mismo centro.

\section{Imagen 4. Portada de un matutino, 05 de Septiembre de 1970}

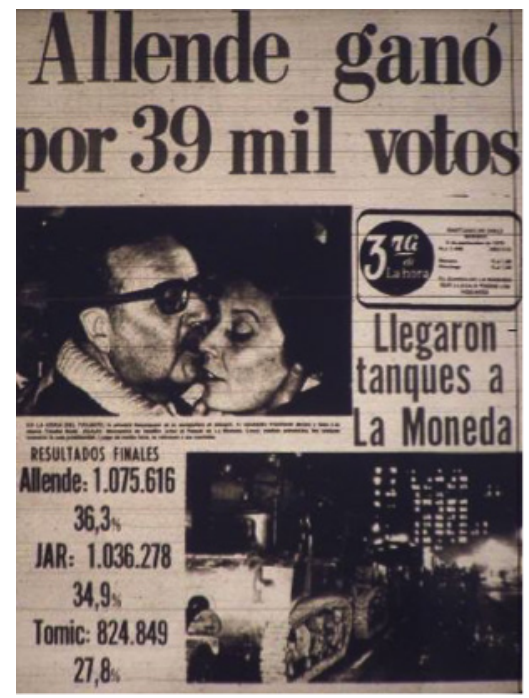

Fuente: Diario La Tercera.

Allende, aparentemente informado por la asonada militar en desarrollo, no se amilanó. Pasadas las 2400 horas del viernes 4 de septiembre de 1970, 
se trasladó al lugar donde ocurría la celebración espontánea y pronunció, en el local que ocupaba la Federación de Estudiantes de la Universidad de Chile $(\mathrm{FECH})$, un discurso de agradecimiento que tuvo mucho de llamamiento a la tranquilidad. Que la sede de la FECH diera por frente a la Alameda, ya no parece sorpresa, tampoco, que su intervención evocara con optimismo las “ (...) esperanzadas alamedas del socialismo" (Martner 1992: 144).

\section{Ama la incertidumbre y serás democrático}

La elección presidencial de 1970, fue tan o más reñida que la de 1964 y a diferencia de la ocurrida en 1958, la de 1970 enlistó a tres y no a cuatro candidatos; la misma cantidad de postulantes en los que se dividió el electorado nacional. La partición de los votantes en tres tercios competitivos ocurrió en el marco de una campaña signada por agrias disputas entre los diferentes comandos. En un giro cada vez más contencioso, los enfrentamientos entre partidarios y simpatizantes de cada uno de los tres candidatos-además de Allende, Jorge Alessandri y Radomiro Tomic- escalaron en beligerancia. La violencia interpersonal conturbó una campaña muy dilatada. No menos de 10 personas fallecieron en el marco de la competencia electoral, mientras que los heridos se contabilizaron por centenares. Asaltos a locales partidarios, riñas entre simpatizantes y toda clase de amenazas, acentuaron un clima tan enrarecido que no fue extraño que también incoara toda suerte de complots. Producido el milimétrico triunfo de Allende, una banda de ultraderecha apertrechada por la Central de Inteligencia Americana (CIA), asesinó al Comandante en Jefe del Ejército, pese a que su objetivo original era apenas secuestrarlo. El impacto provocado por la muerte de un militar constitucionalista como René Schneider, tuvo un efecto inesperado para sus promotores. En vez de impedir el ascenso de Allende, operó como una fórmula para su legitimación.

Entre la elección presidencial y la votación ratificatoria ocurrida ante el Congreso Pleno, los episodios de desestabilización no remitieron. ¿Por qué? Una línea de explicación refiere a la propia administración saliente. En rigor, durante su último año de gestión, el gobierno de Frei intervino en la campaña presidencial de muy diversas maneras. Sin ser una administración populista, durante su término se contabilizaron asignaciones discrecionales de beneficios, muy especialmente de sitios habitacionales. Dos mecanismos fueron los predominantes. De una parte, la distribución selectiva de tierra sin urbanización completa. El caso que mejor retrata dicha actuación aconteció con ocasión del fraccionamiento del fundo La Bandera, en la periferia sur Santiago. Lo que inicialmente había sido un proyecto dentro de un programa habitacional 
que destinaba lotes con servicios a familias beneficiarias, devino en obsequios clientelares por fuera de cualquier prelación u ahorro.

El segundo mecanismo correspondió a la asignación de viviendas terminadas o por terminar a personas distintas a sus adjudicatarios. Pese a la larga tradición de ocupaciones que Santiago exhibe a lo menos desde la década del '30, nunca se había implicado a una alta autoridad del Estado en una operación que incluía cientos de unidades construidas y que ocurría a días del término de una administración afectada por una severa caída en su adhesión.

La desestabilización impulsada desde el gobierno saliente tuvo a otro ministro del gabinete como protagonista. A diferencia de las tomas de suelo promovidas por el MIR, un circunspecto Ministro de Hacienda "se tomó" el horario estelar de la televisión pública para proferir un mensaje calculadamente alarmista (Hurtado, 2013). A través de su alocución, Andrés Zaldívar pronosticó un panorama económico tan incierto como volátil.

El expediente de transformar la realidad desde el discurso arrojó consecuencias inmediatas. La siembra de incertidumbre se desdobló en manifestaciones de temor, pero en ámbitos específicos. A partir del 7 de septiembre de 1970, primer día hábil después de verificados los comicios presidenciales, la inflación de ofertas de bienes raíces provocaron una caída generalizada de los precios del suelo en las zonas donde se concentraban los grupos de más alta renta (Frenz 2006: 84-86). En cosa de días, el descenso afectó incluso a los bienes durables. Aunque fuera imposible corroborarlo, se decía que las familias de la elite vendían sus automóviles en el mismo aeropuerto mientras esperaban vuelo. ¿La razón? La inminente implantación del comunismo.

Alertado por la situación, Allende buscó descomprimir el cuadro. En una maniobra osada y "clasista", el primer gabinete ministerial incluyó a obreros en su formación. A la cabeza del MINVU, el gobernante escogió a un obrero socialista sin estudios universitarios. La elección de Carlos Cortés fue tan importante como el reclutamiento de arquitectos, ingenieros y urbanistas en puestos clave. Cortés, pero también los especialistas convocados al MINVU, debieron lidiar con un verdadero enjambre de expectativas y demandas. En este caso, tanto las que provenían del déficit habitacional, como las que buscaban, con la usurpación colectiva de tierras, sumar ventajas y tomar posición frente a un gobierno de izquierda que se declaraba contrario a toda represión policial.

Por obvio que parezca, es importante subrayar que Allende no eligió las condiciones en las que se inició su presidencia y que, además, inauguró su gestión en medio de una atmósfera cargada de malos presagios. Tal y como se ha insinuado, la conjunción de acontecimientos provocados incluyó desde campañas del terror hasta el retiro masivo de ahorros. No por nada, la incertidumbre se instaló como el primer escollo a vencer. En este cuadro, se 
vuelve más comprensible la preocupación respecto de un desborde popular como el que ya había vivido Lima en la década del ' 50 y ' 60.

Las políticas de vivienda de la UP debutaron afectadas por la deriva populista. Consciente de los peligros sembrados por la administración freísta, Allende se esmeró en persuadir a los tomadores de viviendas terminadas de lo inconveniente de sus actos. Pese a intentarlo, Allende fracasó en convencerlos. Visto su comportamiento, ningún observador externo podía haber sostenido que la transición hacia un Estado socialista estaba comenzando en el MINVU.

Lejos de lo que habían sido algunas experiencias urbanas socialdemócratas, las políticas bajo la UP no solo desestimaron estatizar el suelo -como había ocurrido en los socialismos reales- sino que tampoco intentaron elevar la tributación territorial -incremento en las contribuciones a los bienes raíces- o siquiera aplicar leyes de recuperación de plusvalías urbanas. En rigor, tampoco pusieron en práctica políticas de promoción del arrendamiento. Fieles a una forma atenuada de economía urbana liberal, los nuevos decisores privilegiaron políticas para promover el acceso a la propiedad privada de la tierra. En otras palabras, convertir al pueblo de Chile en propietarios de viviendas en suelos equipados y servidos. Pero, ¿de dónde venía dicho predicamento?

\section{El derecho a la vivienda y a la ciudad}

El Estado debía proporcionar habitación económica en cantidad suficiente y con localización adecuada. La idea, firmemente establecida en la cultura política de las izquierdas latinoamericanas y muy especialmente entre los arquitectos y urbanistas que colaboraron con Allende, suponía que el acceso a la habitación, pero también a la ciudad era un derecho humano consagrado.

Aunque las organizaciones que representaban a los asalariados reivindicaban el acceso universal a la vivienda en propiedad, en muchos países de la región la provisión de habitación barata no significó la universalización del beneficio para el conjunto de los trabajadores. Además estaban los no asalariados. Más numerosos que los obreros contractualizados, su precaria integración laboral en capitales como Santiago de Chile, contrastaba con su creciente visibilidad espacial.

Efectivamente, hasta mediados del siglo XX ni las barriadas ni las personas que las habitaban habían concitado la atención de las políticas públicas, al menos no sistemáticamente. En pocos años esa realidad experimentó un cambio. Hacia 1952, siempre para Chile, la precaria residencialidad de los que ocupaban o sub arrendaban suelo no servido, había adquirido una entidad suficiente como para que el censo nacional de viviendas contabilizara todas las habitaciones, por misérrimas que fueran. 
Desde un punto de vista general, las organizaciones de los sin casa bifurcaron sus actuaciones. La mayoría de sus representados se adecuaron al acceso institucional a la vivienda aunque, en ocasiones, extrajeron del repertorio de la acción directa algunas acciones. Las invasiones de terrenos fiscales, semifiscales o privados, fue la práctica más socorrida. Pero lo que también podríamos definir como la patrimonialización no adquisitiva de un suelo sobre el que no se tiene titularidad, a veces careció de un objetivo residencial. En oportunidades la invasión, tan solo, buscaba elevar la visibilidad frente a alguna reivindicación.

Aunque el Estado mejoró sus prestaciones en lo que a cantidad y calidad de unidades habitacionales se refiere, el camino extra-institucional nunca fue desestimado. Pero a diferencia de lo ocurrido desde 1953 en la periferia desértica de Lima, para el Santiago de la misma época, los ocupantes tuvieron en la fuerza pública un contrincante exigente (Giusti 1973). Salvo excepciones, el rigorismo de la actuación policial extendería su celo represivo hasta marzo 1969. Ese año y en Puerto Montt, una ciudad al sur del país, un destacamento de carabineros asesinó a una decena de pobladores que participaban de una ocupación. Si bien no era el primer desalojo que se saldaba con muertos, la opinión pública mostró señales evidentes de conmoción. La responsabilidad política por la represión policial se convirtió en un asunto que tensionaría al propio oficialismo. En una señal de radicalización, las acusaciones respecto a la autoría intelectual de la masacre, fueron lanzadas hacia la jefatura del gobierno por la propia juventud democratacristiana. La conflictividad interna escaló lo suficiente como para que, meses más tarde, se provocara una división por la izquierda del partido de gobierno. La Democracia Cristiana comenzaba a fisurarse y con ella, el centro político.

Las fracturas en el oficialismo fueron sintomáticas de un cambio de signo en la opinión pública que favoreció una resignificación de la violencia contra bienes y propiedades. Tal y como una fracción de la izquierda venía promoviendo, el desempeño policial fue conceptuado de un modo mucho más negativo que las ocupaciones de suelo. Sin ser del todo aceptadas, las tomas de tierras parecían testimoniar algunas de las muchas injusticias que afligían la sociedad chilena y sobre las cuales giraba el cancionero de protesta. Aunque no existen encuestas que lo acrediten, las invasiones fueron crecientemente comprendidas e incluso justificadas. 
Imagen 5. Toma de terrenos,

Sector Sur-Este de Santiago, 1970

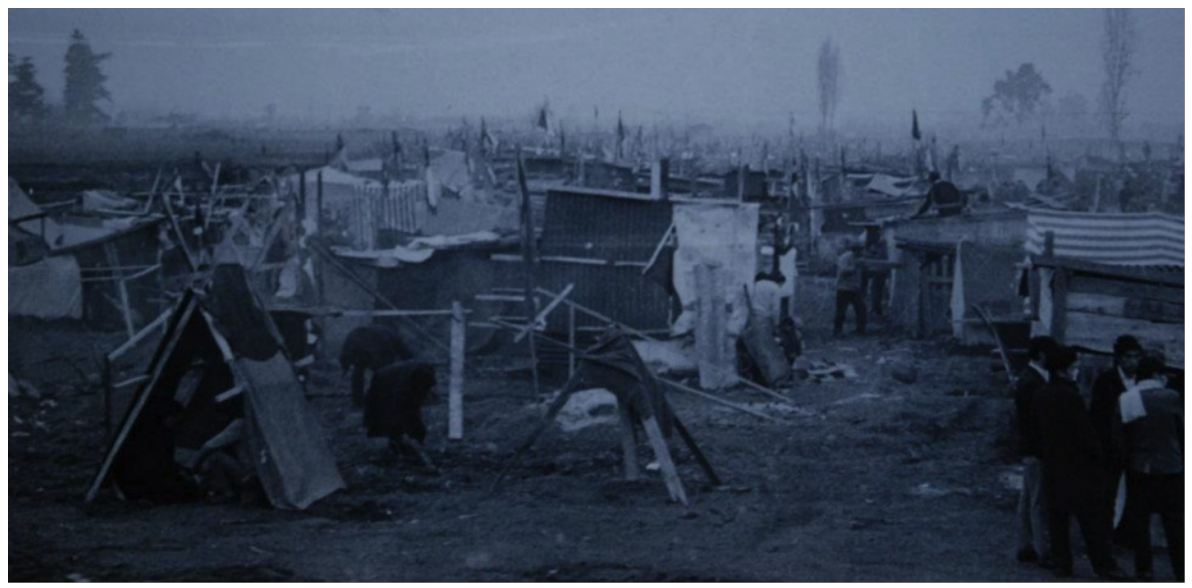

Fuente: http://2.bp.blogspot.com/-1LG8hUxDc9I/T9ixmJNfndI/AAAAAAAAB$\underline{\mathrm{hA} / \mathrm{c} 1 \mathrm{MKpW}-\mathrm{XNgQ} / \mathrm{s} 1600 / 394045 \quad 382939711721484 \quad 100000163757233 \quad 16}$

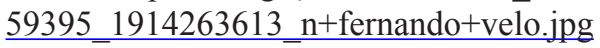

El cambio en el clima de opinión alentó un ciclo de ocupaciones que se desencadenaron en diferentes ciudades. Los desalojos policiales perdieron contundencia sea como consecuencia directa de los sucesos de Puerto Montt, sea por el adelantamiento de una campaña presidencial a tres bandas. Para el año de la elección (1970), las ocupaciones se contabilizaron por centenares. La tolerancia policial tuvo un beneficiario insospechado: el MIR. El Movimiento, una organización mayormente compuesta de militantes jóvenes, pero experimentados, promovió la creación de comunidades autoproducidas a las que llamó de manera desafiante: campamentos.

Podría parecer paradojal, pero los miristas rechazaban la verticalización residencial que prometían los arquitectos, urbanistas y paisajistas que colaboraban con Allende. Los edificios habitacionales que con tanto ahínco se levantarían bajo la Unidad Popular, versiones mejoradas de los proyectados por el MINVU bajo el gobierno democratacristiano, eran repudiados por recluir a los trabajadores y sus familias en virtuales colmenas verticales -aunque la mayoría eran blocks de 4 pisos-. La unidad básica del socialismo en la ciudad, alegaban los pobladores enlistados en el MIR, era la vivienda aislada. Una maquette elaborada con motivo de un Congreso de Pobladores ocurrido durante 
la UP, confirma su filiación formal con las casitas del barrio alto ironizadas por Víctor Jara en su conocida canción.

Como era posible imaginar, el repertorio mirista también incluyó asaltos bancarios y la realización de desplantes en puntos de alta visibilidad. Precisamente y a días de la elección presidencial, un grupo de militantes del MIR ocupó uno de los edificios de la todavía en construcción Remodelación San Borja. Su performance, sucedida de otra a los pies de un monumento a un héroe de guerra, fue una prefiguración de la inflación peticionaria que viviría Allende como tónica de su gobierno. No sería la única diana que tuvo a jóvenes citadinos como protagonistas.

\section{Para entender un happening en el lugar equivocado}

Piedra rajada era el nombre de una roca de grandes dimensiones depositada sobre un paraje precordillerano ubicado hacia el Este pedregoso de Santiago. Su denominación sufriría un inesperado desdoblamiento toponímico - de piedra rajada a piedra roja- por causa del clima político afectado por las elecciones.

La prensa santiaguina que cubrió la realización de lo que apresuradamente se llamó un Woodstock criollo, no dudó politizar la convocatoria a lo que en otras circunstancias no habría sido conceptuado más que como un improvisado festival. Corría octubre de 1970 y la redenominación, admite, como mínimo, nuevas modulaciones. ¿La razón? Roja o rojo en el Chile inmediatamente posterior al triunfo de Salvador Allende no era una expresión inocua, menos que menos si de alguna forma podía relacionarse con el barrio alto de Santiago.

El festival, nombre que adoptaron los jóvenes que fungieron de improvisados organizadores, concitó la concurrencia de varios miles de concurrentes, que ascendieron varios kilómetros hasta encontrarse con un sitio que algunos calificaron de agreste. La comparecencia de una pequeña multitud, -se dice que unas 5.000 personas asistieron a las presentaciones de cuatro bandas de música rock-, tampoco pasó inadvertida.

Las repercusiones mediáticas de lo que un sector de la prensa llamó el "Festival de la Marihuana", escalaron lo suficientemente rápido como para que en pocos días se formara una comisión parlamentaria consagrada a estudiar el consumo de narcóticos entre los jóvenes chilenos. Además, y como represalia en contra del principal organizador del festival, al adolescente se le negó la posibilidad de concluir sus estudios secundarios en el Liceo fiscal donde estaba cursándolos.

Nos equivocaríamos si entendiéramos las repercusiones y hasta las sanciones como una reacción extemporánea. Una editorial del diario $E l$ Mercurio ayuda a comprender el enfoque con que un sector de la elite procesaba 
el episodio. De entrada, el diario más antiguo de América, identificaba parajes precordilleranos de Las Condes como sectores visitados "... por intelectuales disconformes del bullicio metropolitano". A continuación enfatizaba el comportamiento censurable en el que incurrió una fracción de los concurrentes. ¿Alguna explicación para el "descontrol"?: la falta de vigilancia.

Para el matutino, el consumo de drogas explicaba la ausencia de una "conducta recta" entre los asistentes, también llamados inmaduros y hasta escapistas. La editorial se cerraba con una acusación temible: durante el festival se percibió la presencia de extranjeros "acaso deseosos de propagar sus experiencias envilecedoras". Frente a ellos, el editorialista reclama de la autoridad inmigratoria máxima severidad en el examen de lo que sin ambages llamaba "elementos indeseables".

La agresividad que destila el editorial podemos entenderla expresiva del miedo que atenazaba a la elite frente a lo que concebía, nada más, nada menos, como un desplome valórico. El testimonio proporcionado por un hippie, confirmaba lo que realmente estaba en juego. En su declaración, el festival admitía ser un parteaguas, “... una etapa de transición entre dos culturas; una moribunda y otra apenas por nacer". El uso de la expresión transición es expresivo de las reverberancias políticas de un festival que pese a la politización dominante, buscaba diferenciarse de la ideologización en que había incurrido la sociedad.

Aunque la organización del festival había corrido por cuenta de músicos, hippies y siloístas, el miedo elitista a la transición al socialismo era el bajo continuo sobre el que operaba su mirada horrorizada. En esa coyuntura, entre el triunfo de Allende y su entronización como Jefe de Estado, conspicuos integrantes masculinos de la elite participarían del asesinato del General René Schneider. También fue el período en que mujeres maduras e incluso abuelas, se vistieron de luto completo, descendieron hasta el centro cívico y manifestaron su indisposición frente a la colonización marxista que sufría la patria. Todo eso ocurría mientras otros integrantes de la elite vendían sus propiedades a precio de liquidación y escapaban del país.

Sin desestimar las explicaciones anteriores, el escándalo al que fue asociado el festival de Piedra Roja, admite tres lecturas adicionales. En primer lugar, el barrio alto de Santiago ya había capitalizado suficientes amenidades como para ser conceptuado en tanto que "distintivo y bello". Por lo tanto, no parecía, bajo concepto alguno, un lugar adecuado para que ocurriera una reunión concurrida y licenciosa.

Una segunda derivada socio-espacial tiene que ver con la negativa elitista a que en su barrio tuvieran lugar reuniones multitudinarias, mucho más si se trataba de actividades gratuitas. Ese tipo de actividades quedaría reservado para circunstancias enteramente excepcionales. A modo de inventario, es importante 
consignar que en el barrio alto muy rara vez se han concentrado muchedumbres. Las únicas que es posible contabilizar, fueron las autoconvocadas con motivo de la detención internacional de Pinochet o las reunidas con ocasión de sus honras fúnebres.

Un tercer aspecto que El Mercurio soslaya, pero que es importante subrayar, dice relación con la posibilidad de que en un mismo sitio convergieran los hippies de Providencia con los que concurrían a lugares céntricos como el Parque Forestal. Los participantes del festival han testimoniado la convocatoria inclusiva al evento. Reunir a personas de diferentes procedencias sociales bajo un interés común no era algo habitual en el Santiago primaveral de 1970. ¿Por qué?

\section{Alta ciudad, residencialidad exclusiva}

El Santiago de fines de la década del sesenta ya registraba una suerte de división simbólica. Suficientes voces habían repetido que hacia el Este de la Plaza Italia se extendía la fracción conspicua de la ciudad. No era una novedad que distinguiera del todo a Santiago. Desde fines del siglo XIX y al igual que en Buenos Aires, una parte del movimiento demográfico hacia el Este se auto justificó en un argumento sanitario-ambiental: trasladarse en la dirección hacia los faldeos precordilleranos figuraba en muchas prescripciones médicas como un antídoto eficaz para diferentes dolencias. Menos comprensivo, Neruda acusó a "los ricos" de escapar: "con muebles y fotografías / lejos, a la cordillera, / y allí dormían entre rosas...”. ¿Su principal recriminación? Imputarle a los pudientes su cobardía por huir del "centro de la ciudad pobre / con dientes duros de pantera" (1950).

Los recriminados por Neruda no fueron los únicos en preferir como destino residencial el cono de alta renta, que casi sin solución de continuidad se extendía hacia el Este de la ciudad. El problema es que también tomaron un camino parecido los que nunca debieron haber realizado algo semejante. Por ejemplo, los primeros organismos internacionales avecindados en el país.

Cuando la Facultad Latinoamericana de Ciencias Sociales (FLACSO) se emplazó en Ñuñoa, en una de las instalaciones de la Universidad de Chile, la CEPAL ya había desestimado ubicarse en el centro de Santiago. Ambas organizaciones, reproduciendo un patrón de localización que venían exhibiendo algunos empresarios y profesionales liberales, se radicaron en Providencia, Las Condes o Ñuñoa. Para los funcionarios internacionales fue una opción que les permitió reducir sus desplazamientos laborales a caminatas por vecindarios "encantadores y tranquilos", para seguir con la reveladora descripción empleada por un intelectual socialista (Jobet 1975). En el caso de FLACSO, su ubicación 
ñuñoína fue objeto de controversia interna. Una fracción de sus integrantes prefería la "señorial” Providencia. ¿La razón? La última comuna ofrecía más "empaque".

\section{Imagen 6. Avenida Providencia esquina Avenida Ricardo Lyon, 1958c}

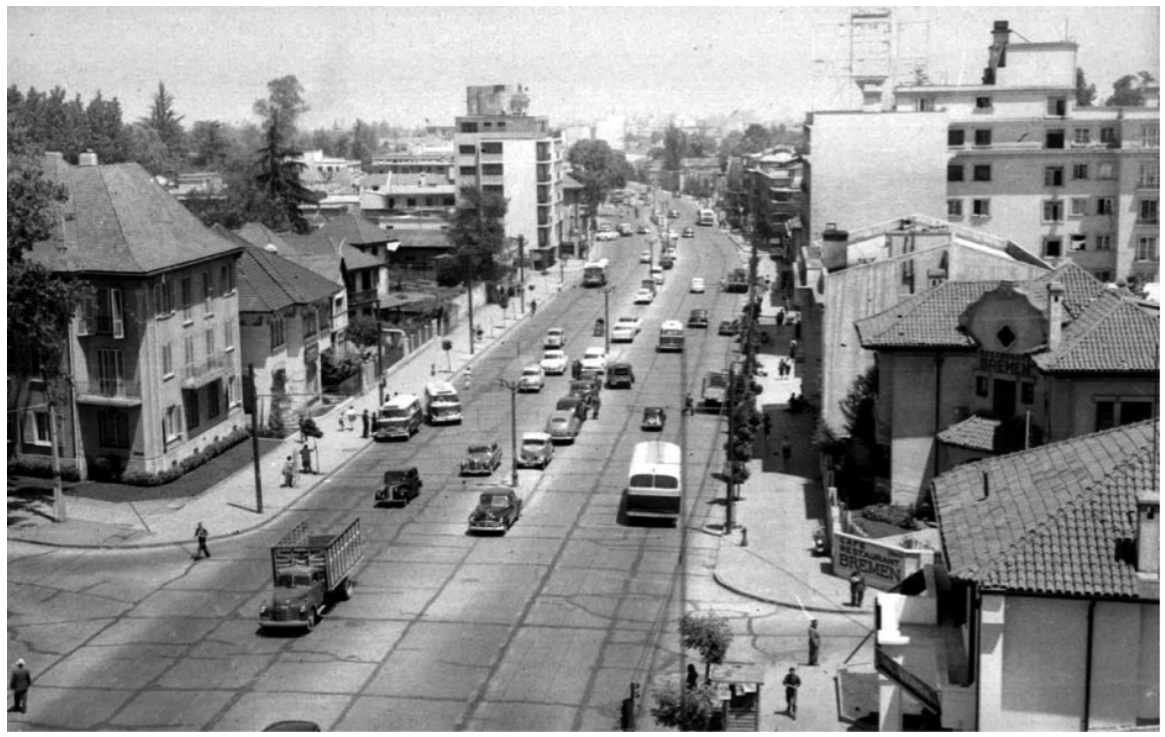

Fuente: Archivo digital de Alberto Sironvalle.

La cultura suburbana identificada con la casa aislada, premunida de antejardín y jardín, y exenta de usos "indeseables", fue objeto de nutrida atención publicitaria, artística y también cinematográfica. No es necesario hablar de su importancia para el reforzamiento de estereotipos. Ya en la década de los sesenta, películas como Un viaje a Santiago (1960) o El burócrata González (1964), anticiparon la tendencia que luego se convertiría en dominante atendida la geografía residencial del poder político, Allende dixit. Cada uno de esos largometrajes incurre en el didactismo de enseñar la vivienda de un parlamentario o de un ministro en ejercicio. En ambos casos la vivienda es una residencia aislada y su localización correspondería a Las Condes. Con un dejo autocrítico, Eduardo Frei, afirmaba también hacia 1960 que:

Vivo en el barrio alto. Cuando paso por la Avenida Apoquindo, la encuentro preciosa y me alegro, con egoísmo, de vivir en una ciudad bella. Pero cuando, en diez minutos de viaje en automóvil, llego a la población José María Caro y veo la tierra- porque ayer hasta la cabeza la tenía color plomo-. Cuando observo 
a los niños, digo ‘¿Hay derecho para que algunos estemos en Europa, y otros, en un cuarto de hora de viaje, estén dentro del Africa? ¡No hay derecho! (1993:

282-284).

La caracterización del barrio alto como como "ciudad aparte" y destino pudiente admitió críticas tempranas. Sebreli, sobre el barrio alto, despachó varios cuestionamientos. En su parecer, la zona constituía un sector menos accesible que otros debido a su condición de residencia de la alta burguesía. El autor de Buenos Aires, vida cotidiana y alienación no sólo insinuaba que sus habitantes eran compradores de exclusividad, sugería además que la ausencia relativa de transporte público no podía ser entendida como una casualidad.

En rigor, mientras las críticas de Neruda y Sebreli podemos entenderlas como un cuestionamiento a la periferización elitista, la homogeneidad social ocasionada por el "enclaustramiento excluyente" solo podía acreditarse, durante la década del sesenta, en algunas zonas de la comuna de Providencia. No ocurría lo mismo en toda la extensión administrativa que correspondía a Ñuñoa ni tampoco en Las Condes, cuyo desarrollo urbano incluía, de manera más intensa, la presencia de poblaciones y asentamientos irregulares.

\section{Baja ciudad, política popular}

Mientras Santiago experimentaba un acelerado proceso de suburbanización, la dispersión residencial en baja densidad no fue el único resorte que la ciudad contabilizaba como mecanismo expansivo. En la dirección exactamente opuesta al Este, otra periferia se estaba configurando y reconfigurando.

Hacia fines de la década del '60, una nueva expresión apareció en el habla de la ciudad de Santiago: casco histórico. Su uso precedió la implantación de un término que tendría mayor uso: Santiago poniente. Mientras Santiago poniente buscaba señalizar algunos barrios que las élites habían dejado después de migrar hacia el Este precordillerano, casco histórico evocaba una tradición de apariencia noble. Pero, ¿qué clase de ciudad es la que se estaba dilatando más al Occidente del casco histórico?

Existen zonas y comunas de Santiago de fuerte raigambre popular y Las Barrancas siempre exhibió dicha característica. Espacio de confluencia de asentamientos irregulares, fraccionamientos y proyectos de vivienda de origen fiscal, su trayectoria incluyó una contundente presencia rural.

Precisamente, y durante el siglo XX santiaguino, el Occidente de la ciudad fue una de esas áreas políticamente activadas donde la asociatividad campesina despuntaba con líderes carismáticos y huelgas. También es necesario reconocer el quehacer reivindicativo movilizado por decenas de organizaciones de pobladores. En Las Barrancas, "agregados" "mejoreros", "compradores de 
sitios a plazo", arrendatarios, "callamperos" y pobladores, dieron vida a un denso tejido social que alimentó desde concurridos cabildos hasta paralizaciones anti-autoritarias.

Durante los largos sesentas, la parte urbana del paisaje comunal adoptó un sello distintivo. Mientras en algunos de sus bordes construidos se localizaron conjuntos de interés social. El panorama no había cambiado demasiado hacia comienzos de 1980. Según un estudio realizado para Pudahuel, una de las comunas derivadas de la subdivisión de Las Barrancas, la autoconstrucción alcanzaba al $70 \%$ de las viviendas.

De ninguna manera debiéramos entender el Santiago Oeste como una zona aislada. Atravesada por el viejo, pero también por el nuevo camino a Valparaíso, Las Barrancas fungió por décadas como una estación de tránsito hacia y desde la segunda conurbación del país. La integración se radicalizaría en los precisos momentos en que el poblamiento popular debía lidiar con abultados déficits en infraestructura y equipamiento. Hacia fines de los ' $50 \mathrm{~s}$, el ejecutivo adoptó una decisión crucial para el destino de esta área: el nuevo aeropuerto internacional de la ciudad se edificaría en uno de los muchos fundos del Pudahuel rural. Al igual y como había ocurrido en otras ciudades, la inauguración de la nueva terminal aérea en 1967 detonaría poderosos cambios, aunque su efectiva irradiación no se advertiría sino después de varias décadas.

Lejos de identificarse con la figura del "patio trasero" de Santiago, la significación política y cultural de Las Barrancas fue innegable. Política, porque el Oeste de Santiago había devenido desde 1960 en bastión principalmente comunista, cuestión que Jorge Giusti captó tempranamente. Alcaldes, regidores y un amplio repertorio de dirigentes forjaron una constelación de organizaciones donde las deportivas jugaban un papel fundamental. Cultural, porque el Occidente era una zona de contacto donde sobrevivía una rica tradición agrícola en proceso de des-campesinización. No por nada, Violeta Parra elevó a Las Barrancas a la condición de hito en sus investigaciones folklóricas. 


\section{Imagen 7. La campaña presidencial en el Oeste de Santiago, 1970}

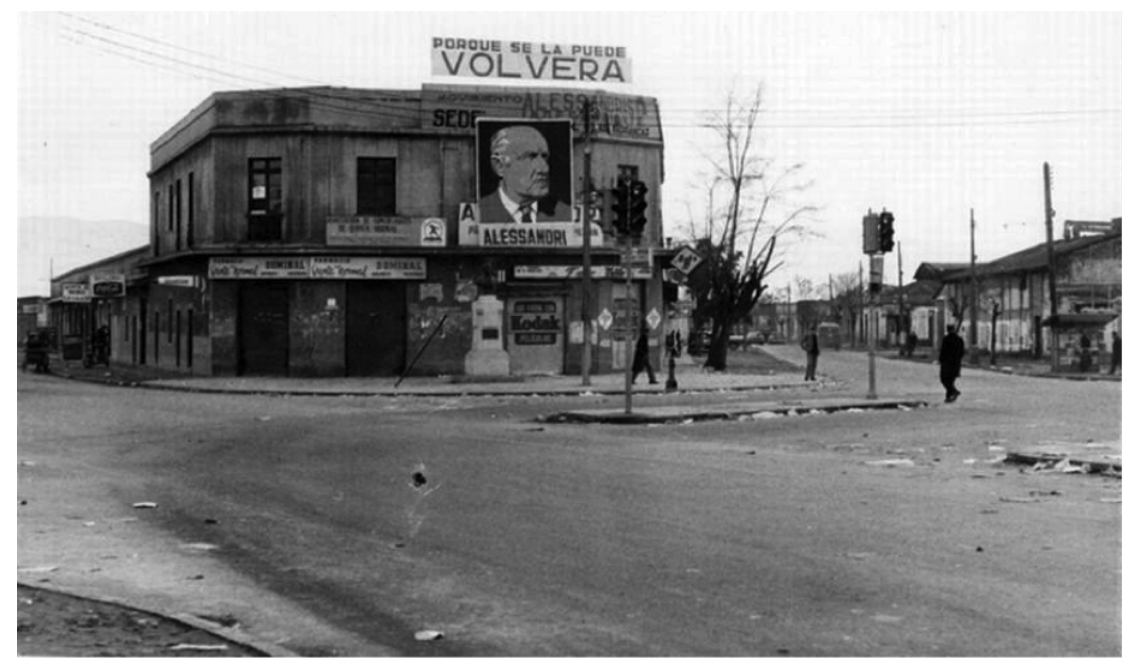

Fuente: Archivo digital de Alberto Sironvalle.

Más conocida es la gravitación que el Occidente popular tuvo para la producción musical de Víctor Jara. En 1972, precisamente, apareció el disco La Población. Las canciones de larga duración -una de las cuales compartía en autoría con el dramaturgo Alejandro Sieveking-, relevaron las esperanzas de los sectores populares con especial acento en sus luchas y padecimientos. En una de sus más conocidas canciones, el plurifacético artista inmortalizó a Luchín, el niño descalzo del Barrancas poblacional, tan "frágil como un volantin” en el perceptivo parecer de Jara.

\section{Conclusión}

Cuartel general de todos los poderes del Estado, la capitalidad que Santiago detentaba desde antaño, le confirió un papel indiscutible bajo la UP sea cual sea la trilogía que se acepte: fiesta, drama y derrota o conflicto, crisis y fracaso. Devenida en sede ejecutiva de la vía chilena al socialismo, Santiago se convirtió en un producto único de la Guerra Fría y aunque compartía con La Habana su subdesarrollo material y con Moscú su carácter periférico, el antagonismo, al menos hasta mediados de 1973, no era lo suficientemente explosivo como para pensar que sufría un proceso ineluctable. De ninguna manera ineludible si, especialmente, observamos el funcionamiento de instituciones atentas a 
las relaciones entre estabilidad institucional y profundización democrática. Al respecto y de la decena de organismos internacionales que funcionaban en Santiago hacia septiembre de 1970, tan solo el Centro para el Desarrollo Económico y Social de América Latina (DESAL), dejó de operar en el país como consecuencia del triunfo de Allende. CEPAL, FLACSO y más tarde la socialdemócrata fundación Friedrich Ebert, acreditaron en la ciudad, incluso en el Santiago contencioso de la UP como base de operaciones latinoamericanas. Pero, ¿por qué hacerlo? En rigor y mientras varios países sudamericanos se mantenían o ingresaban en espirales autoritarias (Paraguay, Brasil y Argentina) o sufrían el rigor de experiencias guerrilleras de alta impacto público (Uruguay y Argentina), la sociedad chilena y muy especialmente la santiaguina parecía afectada, pero no perforada por la trilogía compuesta por democratización, urbanización y sobre movilización.

El artículo ha proporcionado algunas pistas sobre la capacidad de resiliencia, pero es necesario subrayar dos que se agregan al stock de atractivos que la sociedad rezumaba: altas dosis de pluralismo político e irrestricta libertad de expresión. Sin concebirla como una república modélica, lo cierto es que el reformismo democrático de la UP sobrevivió más allá de lo que sus opositores declaraban.

Distinto nos parece que fue el panorama a mediados de 1973. Tal y como ocurre cuando se verifica un poderoso sismo, el suelo democrático ya rozaba el estado de licuefacción. La analogía es discutible, pero ilustra un cuadro de inestabilidad generalizado. Cuestionada por burguesa y sospechada por transigente, la plasticidad que distinguía la democracia le había permitido lidiar, incluso, con una transición al socialismo. No era una anomalía ni estaba aislada. Una exuberante cultura política venía sufragándole una elasticidad sobresaliente. Pero pese a la resiliencia del arreglo democrático chileno, el andamiaje institucional que la estructuraba venía sufriendo toda clase de socavamientos; soportar, en simultáneo, presiones centrípetas y centrífugas, puede desfondar la tradición republicana más orgullosa.

Para cualquier observador atento, las alarmas estaban suficientemente encendidas cuando la mayoría de la Cámara de Diputados declaró, en agosto de 1973, la ilegalidad del gobierno de la UP. Antes de eso, como un mensaje sangriento, algunos oficiales y soldados habían protagonizado una insurrección militar.

La lista de episodios contestatarios y muchas veces facciosos, agobiaba a varios protagonistas de época. Para un puñado de testigos, Chile avanzaba hacia el despeñadero. Radomiro Tomic sostuvo, apenas días antes del Golpe de Estado, que la crisis podía ser ejemplificada al modo de una tragedia griega. Qué tan dramático sería su desenlace fue algo que el ex candidato presidencial dibujó sin inhibiciones. Todavía escéptico del sentido adelantó sin ambages 
que "(...) entre todos estamos empujando la democracia chilena al matadero" (Tomic 1988: 462).

Tomic hablaba por lo que leía y escuchaba, pero también por lo que veía y palpaba. Su reflexión, la de un político mundano, sincronizaba con lo que acontecía en el teatro central de la política chilena: Santiago. La capital, pero en especial su microcentro, registraba cuadros de continua anormalidad. La palabra crispación no se pronunciaba, pero los enfrentamientos callejeros solían preceder la realización de manifestaciones multitudinarias. Las demostraciones de fuerza eran parte del paisaje diurno. Mientras transcurrían, por momentos en intranquila paz, las calles-corredor organizadas en damero podían convertirse en un amplificado cuadrilátero pugilístico. Era usual que para cada desfile, marcha o concentración la nómina de lesionados incluyera hospitalizados. La crónica político-policial también registraba asesinatos.

Durante días, la ciudad era conmovida por estallidos de antagonismo. Para algunos no se trataba más que de lucha de clases abierta, para otros, nada menos que la antesala ritual de una conflagración inminente. La exacerbación partidaria, multiplicada por un sistema de medios de comunicación que rivalizaban en su encarnizamiento, terminaron justificando una idea peligrosa: Chile y también Santiago se encontraban en una situación de pre-guerra civil. 


\section{Referencias bibliográficas:}

Aggio 2008: A. Aggio. El momento de Allende: entre la reforma y la revolución. En Ortiz, E. (Ed.) Un siglo con Allende, pp.27-46 (Rancagua, 2008).

Alvarez 2012: M.J. Alvarez. Las invasiones de tierras y la izquierda en la ciudad: Montevideo, Uruguay, 1984-2011. Revista de Ciencia Política, vol. 32, n 2, pp. 411-431 (Santiago, 2012).

Cavalletti 2010: A. Cavalletti. Mitología de la seguridad. La ciudad biopolítica (Buenos Aires, 2010).

Drake 1992: P. Drake. Socialismo y populismo: Chile 1936-1973 (Valparaíso, 1992).

Frei 1993: E. Frei. Obras Escogidas (Santiago, 1993).

Frenz 2006: H. Frenz. Mi vida chilena. Solidaridad con los oprimidos. (Santiago, 2006).

Garcés 1974: J. Garcés. El Estado y los problemas tácticos en el gobierno de Allende. (Ciudad de México 1974).

Giusti 1973: J. Giusti. Organización y participación popular en Chile. El mito del hombre marginal (Santiago-Buenos Aires, 1973).

Vera 1977: H. Vera. Apuntes sobre el modelo chileno: redentorismo militar. En Gil, Federico et. al. [Eds.].Chile 1970-1973. Lecciones de una experiencia. (Madrid, 1977).

Klein 2010: N. Klein. La Doctrina del Shock. El auge del capitalismo del desastre. (Madrid, 2010, 701).

Hurtado 2013: S. Hurtado. El golpe que no fue Eduardo Frei, la Democracia Cristiana y la elección presidencial de 1970. Revista del Centro de Estudios Públicos, n 129, pp. 105-140 (Santiago, 2013).

Kotler et. al. 2007: P. Kotler et.al. Marketing internacional de lugares y destinos. Estrategias para la atracción de clientes y negocios en Latinoamérica (Ciudad de México, 2007).

Jobet 1975: J.C. Jobet. Despedida melancólica. Occidente, n 253, pp. 5863 (Santiago, 1975).

Lawner 2013: M. Lawner. Memorias de un arquitecto obstinado. (Concepción, 2013).

Labrousse 1973. A. Labrousse. El experimento Chileno. ¿Reformismo o Revolución? (Barcelona, 1973).

Levitsky 2011: S. Levitsky. The resurgence of the Latin American left. (Baltimore, 2011).

Magasich 1998: J. Magasich (ed.) Chili pays laboratoire. (Bruxelles 1998).

Martner 1992: G. Martner (comp.). Salvador Allende 1908-1973. Obras Escogidas (Santiago- Madrid, 1992). 
Neruda 1950: P. Neruda. Canto General (Ciudad de México, 1950).

Ossandón 1962: C. Ossandón. Guía de Santiago (Santiago, 1962).

Sabatini et al. 2003: F. Sabatini et. al. Segregación residencial en las principales ciudades chilenas: Tendencias de las tres últimas décadas y posibles cursos de acción, Eure, n 82, pp. 21-42 (Santiago, 2003).

Sebreli et al. 1968: J.J. Sebreli. Buenos Aires, Santiago de Chile: ida y vuelta (Buenos Aires, 1968).

Tomic 1988: R. Tomic. Testimonios (Santiago, 1988).

Touraine 1974: A. Touraine, Vida y muerte del Chile popular (México, 1974).

Valdés 1989: J.G. Valdés. La Escuela de Chicago: Operación Chile (Buenos Aires, 1989). 